\title{
GIS APPROACH FOR CALCULATING MAXIMUM RUNOFF: A CASE STUDY IN BULGARIA
}

DOI: http://dx.doi.org/10.18509/GBP.2020.86

UDC: 528.93:004]:551.311.21(497.2)

\section{Daniela Zlatunova}

Sofia University "St. Kliment Ohridsky", Bulgaria

\begin{abstract}
A number of methods have been developed in hydrological practice to calculate maximum runoff. However, many of them are highly uncertain of the results obtained due to the poor quality of the maximum water quantity data. The challenge is also to calculate the maximum runoff in watersheds for which there are insufficient and / or no observations at all. Such is the case with the catchment area of the Skat River, where during the period 3.08. - 7.08.2014 catastrophic flood occurs. As a result, the town of Mizia was flooded, material damage was caused, dozens of houses were completely destroyed, and two people were killed. The hydrometric station near Mizia is also carried away from the water. In this connection, the purpose of this publication is also to calculate the maximum water quantity of the high wave that caused the flood of Mizia in the absence of high wave data.

To achieve this goal, an integrated GIS with hydraulic calculations approach is applied, allowing the reconstruction of the actual flooded area outside and within the boundaries of Mizia. The reconstruction of the flooded area was carried out on the basis of a total of 29 landmarks taken with a GPS device. In the absence of landmarks, the flooded area was reconstructed using a satellite image from 14.08.2014, taken by the Landsat 8 satellite. The main results of the study are the reconstructed and modeled floodplain, the calculated volume and the maximum runoff of the high wave flooded the town of Mizia.
\end{abstract}

Keywords: GIS approach, maximum runoff, flood, Mizia, Bulgaria

\section{INTRODUCTION}

In the hydrological practice, a number of methods have been developed to calculate the maximum runoff. However, many of them have a high degree of uncertainty about the results obtained due to poor quality data on maximum water quantities. It is also a challenge to calculate the maximum outflow in catchment for which there are insufficient and/or no observations at all. Such is the case for the catchment area basin of the river Skat which is the subject of research and where during the period $3.08-7.08 .2014 \mathrm{a}$ catastrophic flood occurs. As a result, the city The Mizia is flooded, there are two human casualties, material damages, and dozens of houses are completely destroyed. The Hydrometric station in the town of The Mizia is also blown off by the water. In this regard, the purpose of this publication is to calculate the parameters of the high wave (maximum water quantity and volume) that caused the flooding of the city of Mizia in the absence of data on the high wave itself. For the purpose of the subject the application of an integrated GIS and hydraulic calculations approach, by which to determine the water quantity and volume, thus able to provide at least $90 \%$ compliance with the actual/reconstructed flooded area. 


\section{MATERIALS AND METHODS}

Integrated GIS approach with hydraulic calculation includes the following stages: Creating a digital elevation model (DEM) within reach of the city of Mizia, Reconstruction of the flooded area in GIS at the town of Mizia during the flooding 3.08.2014-5.08.2014; Preparation of hydraulic model applicable to the conditions of the pool of the river Skat in the region of Mizia. [3] For the creation of the DEM of the town of Mizia with satisfactory accuracy, all available sources of information are used: a digital cadastral map of the city of Mizia in M 1:1000; topographic map in scale 1:5000; Digital elevation model generated by filming of the Orthophoto card of Bulgaria in 2011. - Unit 2, Unit 7 and Unit 8; Information from direct geodesic filming of the transverse profiles and hydro technical facilities of the river Skat along the city of Mizia. The relief of the river valley was recreated on the basis of the information from the geodesic filming of the transverse profiles of the river. Furthermore, the DEM is supplemented with information about the geometry of the various/separate hydro technical structures in the river section, subject to the study. A total of 42 transverse profiles were captured (including 4 of them on bridges and 38 profiles which outline the peculiarities of the riverbed). [1] The existing railway lines and roads of the Republican road network, as well as the dyke of river Ogosta, are modeled. (Fig. 1)

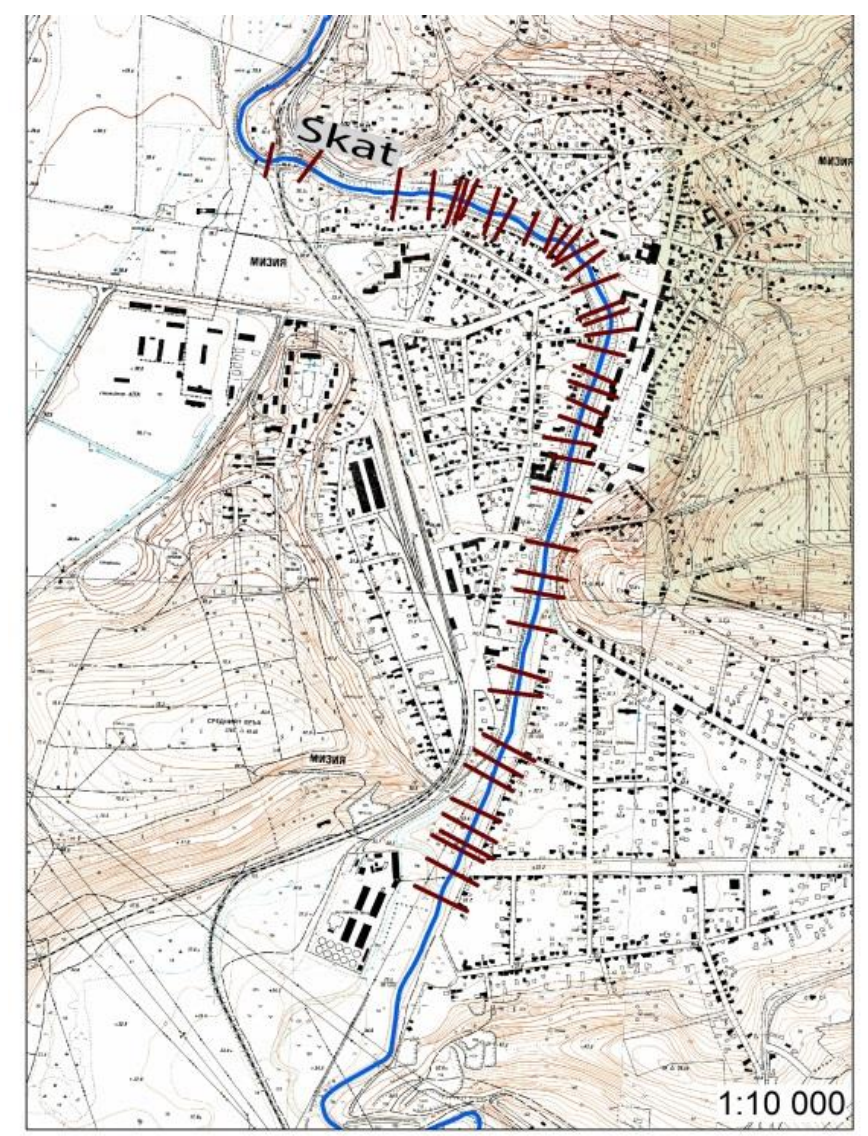

Figure 1. Diagram of the captured transverse profiles of the river Skat at the town of Mizia

For the reconstruction of the flooded area of the town of Mizia the altitude data and the coordinates of a total of 29 GPS-captured pinpoints were used; A helicopter-made photo of the flooded area of the town of Mizia; Orthophotmap of Bulgaria, filming 2011; Digital 
Elevation Model (DEM); Satellite image of the flooded area, located north of the town of Mizia.

The process of reconstruction of the flooded area in the section of Voyvodovo - Town of Mizia (right and left of the main road in the direction of Voyvodovo - Mizia) includes several steps: Implementing of the GPS-pinpoints in GIS; Specification of the location of the landmarks on the photos taken from the helicopter; Clarification of the location of the landmarks on the Orthophotocard in the area of the river spill during the flood; Comparison of the captured altitude of the GPS landmarks and the generated digital elevation model (DEM). (Fig. 2)

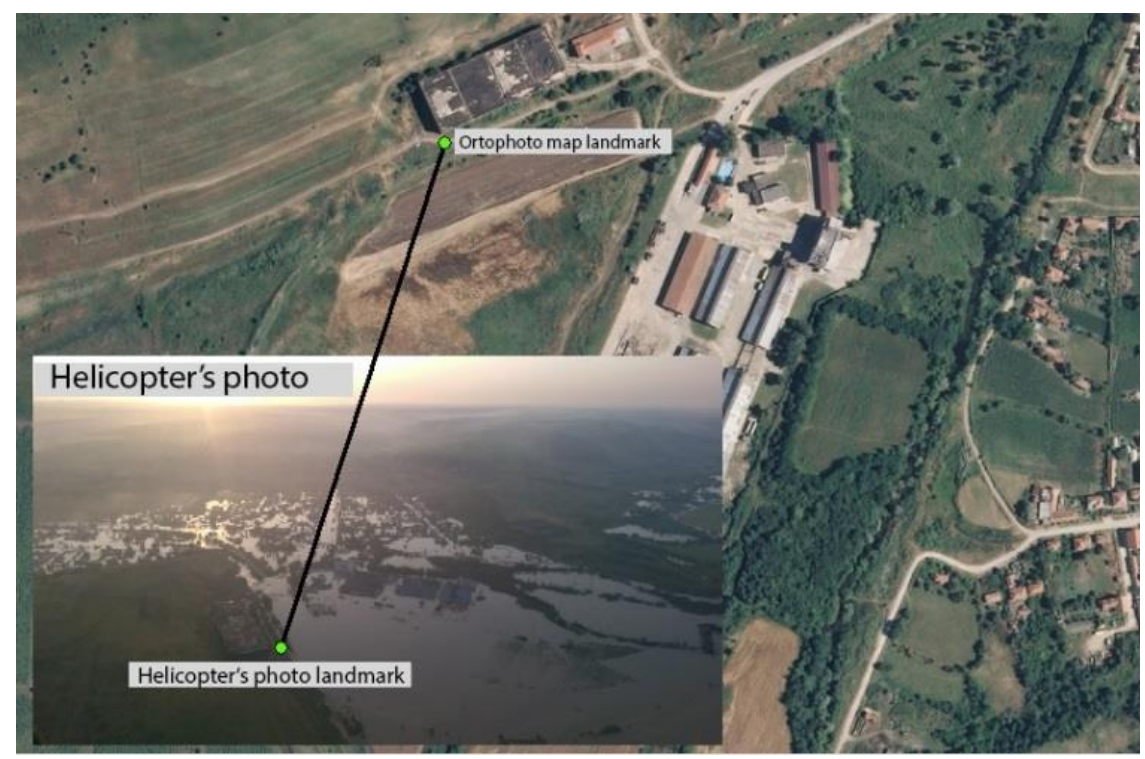

Figure 2. Specifying the location of the landmarks

Hydraulic calculations have been carried out for the calculation of the maximum runoff of the high wave, inundated the town of Mizia. They have been implemented with the help of 1D Matematic Model HEC-RAS (Hydrologic Engineering Center - River Analysis System) version 4.1. developed by the U.S. Military Engineers Corps. The model allows the calculation of a number of hydraulic parameters of the current, such as the depth of the current (the elevation of the free water surface), the width of the water mirror, the energy line elevation, the slope of friction, the speed of The current, the critical depth (the elevation of the line of critical depths), the volume of water under the calculated profile and the hydraulic regime in which the water flow is moved in each examined section.

\section{RESULTS}

\section{Created digital elevation model}

DEM of the town of Mizia includes a river section with a length of $14.5 \mathrm{~km}$ and at a distance of about $500 \mathrm{~m}$ on both sides of the river Skat. Using the "Topo to raster" tool based on the created vector data, a digital elevation model (DEM) is generated with a cell size of the bitmap $1 \mathrm{~m}$. (Fig. 23) For the purpose of this publication, both raster (grids) and TIN digital elevation models have been generated. 


\section{Reconstructed flooded area}

On the basis of the listed sources the flooded area during the flood (from 2.09.20143.09.2014) is reconstructed. (Fig. 3)

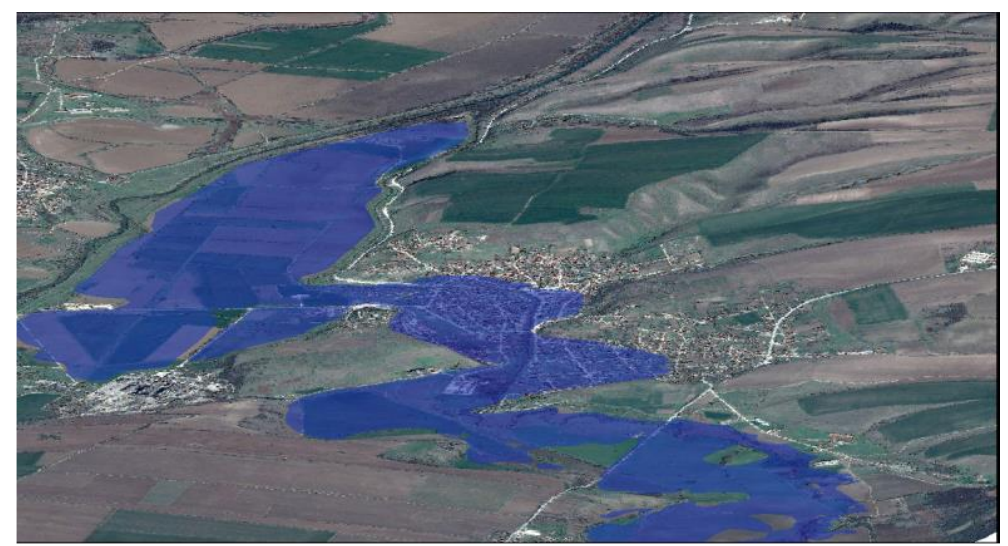

Figure 3. Reconstructed flooded area (3D) in the section Voyvodovo - Town of Mizia.

As there is no information (captured landmarks and photos) for the flooded area north of the city of Mizia (along the dug dyke of the River Skat), it was reconstructed with the help of a satellite image from 14.08.2014, taken from the Landsat 8 satellite. The satellite image has a spatial resolution of $30 \mathrm{~m}$ (i.e. pixel $30 \mathrm{~m}$ ). The final reconstruction of the flooded area, located between the corrections of the rivers Ogosta and Skat and outside the urbanized territory of town Mizia is carried out using the generated DEM. (Fig. 4)

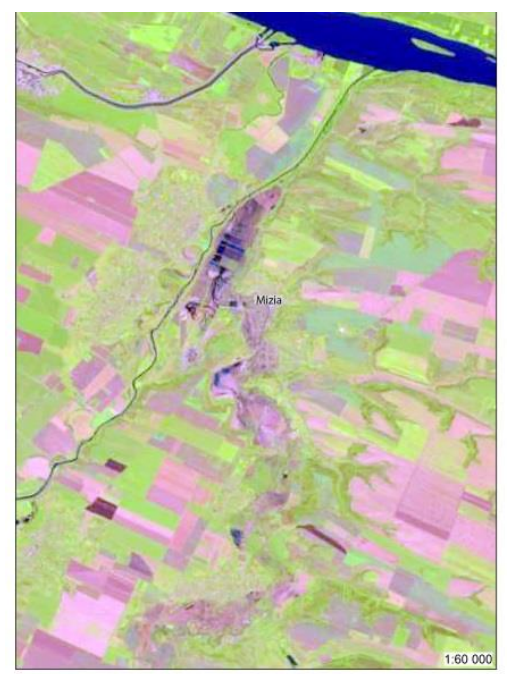

Figure 4. Satellite image of the flooded area located north of the city of Mizia from 14.08.2014

The total reconstructed flooded during the flood area was $8.9 \mathrm{~km}^{2}$.

\section{Calculating the depth of flooding}

The reconstructed continuous water surface is crossed with the topographic surface, represented by the digital elevation model (DEM). Previously, a continuous water surface was converted into a symmetrical TIN network, on the basis of which the difference between the water level and the elevation of the terrain was determined. Positive values represent the areas that are flooded, the negative and zero values represent the unflooded 
(dry) areas. The resulting image actually represents the depth of flooding in the region of the town of Mizia (Fig. 5).

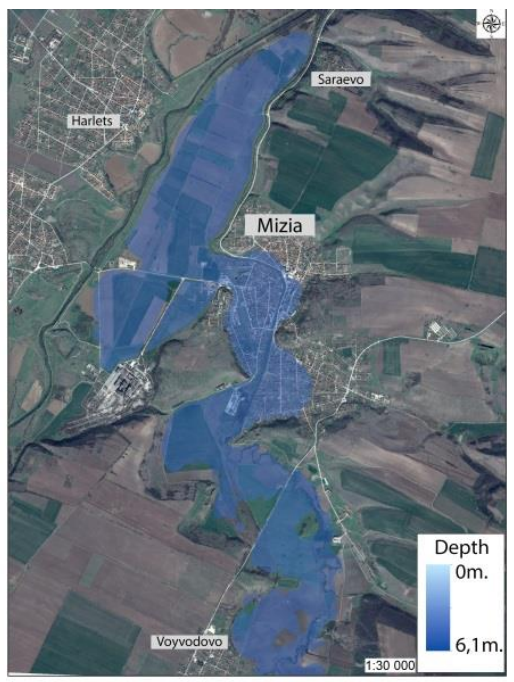

Figure 5. Depth of flooding in the region of the town of Mizia

On the basis of information given by eyewitnesses of the flood and the digital cadastral map of the city of Mizia a calibration of the reconstructed flooded area and the calculated depth of flooding with the actual flooded area and measured area during the flood depth of pouring had been carried. The comparison between the reconstructed and the described flooded area (information from the eyewitnesses of the flood) flooded area and depths indicate almost complete coincidence. (Table 1)

Table1. The flooded quarters and streets of testimony

\begin{tabular}{|l|c|}
\hline \multicolumn{1}{|c|}{ Inundated streets and quarters } & $\begin{array}{c}\text { Depth, } \\
\text { m }\end{array}$ \\
\hline $\begin{array}{l}\text { A strong current between the streets "Dafina Cherkaska" and "Milin kamyk" continued on } \\
\text { "Sergei Rummyantsev". }\end{array}$ & 4 \\
\hline $\begin{array}{l}\text { The neighborhood between the streets "Sophrononius Vrachanski", "Lyuben Karavelov", } \\
\text { "Georgi Dimitrov" and "Milin Kamak" was flooded, second significant in its size flooded area }\end{array}$ & 1,5 \\
\hline $\begin{array}{l}\text { On my arrival on the road between the village of Krushovitsa and the village of Voyvodovo } \\
\text { the road was flooded with a depth of 70 cm and from there it could have been crossed only by } \\
\text { heavy machinery. }\end{array}$ & 0,7 \\
\hline On my entry into the city the area from St. "Slivnitsa" to the school was also flooded. & \\
\hline $\begin{array}{l}\text { De facto the city was blocked - from St. "Petar Atanasov" from the bridge to the warehouses } \\
\text { for secondary raw materials - from 1.0-1.5 m. }\end{array}$ & $1,0-1,5$ \\
\hline $\begin{array}{l}\text { There was Less water on the streets "Hristo Yakimov", "Veslets", "Volov" where there were } \\
\text { blocks of flats from 1 to 6 and the cellars were flooded and maybe about 0,30-0,40 m of water } \\
\text { on the sidewalks. }\end{array}$ & $0,30-$ \\
\hline
\end{tabular}

\section{Calculating the volume of the high wave}

The volume of the high wave is calculated using the Polygon Volume tool, which is found in the 3D analysis of ArcGIS, version 10.3. The calculated volume is 30.5 million $\mathrm{m}^{3}$. According to the witnesses' evidence, the area thus reconstructed $\left(8.9 \mathrm{~km}^{2}\right)$ was completely flooded from $00 \mathrm{~h}$ of 03.08 .2014 to $12 \mathrm{p} . \mathrm{m}$. of 05.08 .2014 . Therefore, the volume of the high wave is estimated at 76.24 million $\mathrm{m}^{3}$. According to letter 703604/13.08.2014 (Irrigation systems JSC), 03.08.1014, the dyke of the correction of Ogosta River was cut. The water level of the space between the two rivers and that of the 
river Skat are leveled and $20-25 \mathrm{~m}^{3} / \mathrm{s}$ start to drain into Ogosta river. For the period from $12.00 \mathrm{~h}$ on 03.08 .2014 to $12.00 \mathrm{~h}$ on the 05.08 .214 about $4.59 \mathrm{mln} . \mathrm{m}^{3}$ are drained into the Ogosta river. Thus, the volume of the high wave, formed from $00.00 \mathrm{pm}$ at 03.08 .2014 to $12.00 \mathrm{~h}$ of 05.08 .2014 , is estimated at 80.83 million $\mathrm{m}^{3}$.

\section{Created hydraulic model}

For the calculation of the maximum runoff of the high wave a one-dimensional hydraulic model (1D) is adapted. The area of study is $\mathrm{L}=8600 \mathrm{~m}$ long and covers the area south of Mizia to the confluence of the Skat River in Ogosta River - to the north. In this section the riverbed has a small slope which moves around $\mathrm{I}=0.001$ and less in certain sections. The coefficient of roughness is $n=0.067$ for riverbed type: Overgrown, unequal, winding river. In order to build the model with maximum accuracy and to obtain maximum plausible results, additional factors influencing the current are taken into account. Using the hydraulic model, stationary simulations were performed in various water quantities: $\mathrm{Q}_{1}=700 \mathrm{~m}^{3} / \mathrm{s} ; \mathrm{Q}_{2}=800 \mathrm{~m}^{3} / \mathrm{s} ; \mathrm{Q}^{3}=900 \mathrm{~m}^{3} / \mathrm{s} ; \mathrm{Q}_{4}=1000 \mathrm{~m}^{3} / \mathrm{s}$. A map of the flooded areas is drawn up for each individual stretch on the basis of the obtained values. Hydrographs of the water quantities in the transverse profiles of the model, velocities of the current, as well as a number of other parameters are obtained as a result of the calculations. [3]

\section{DISCUSSION}

The parameters of the high wave which flooded the city of Mizia and calculated by the GIS and the hydraulic calculation approach are summarized in table 2. The analysis of the results shows that the best match between the modelled and defined by the GIS approach flooded area is obtained with a maximum water quantity of $1000 \mathrm{~m}^{3} / \mathrm{s}$. In this case, the modelled flooded area constitutes $83.2 \%$ of the area defined by the GIS approach. The difference between the two areas occurs as a result of the fact that the hydraulic model only covers the urbanized territory of the city of Mizia, while the reconstructed through GIS area, also covers a territory north of the city of Mizia (along the dyke dug on 02.08.2014 at the river Skat).

Table 2. Analysis of the results of GIS and hydraulic calculation approach

\begin{tabular}{|l|l|l|l|l|l|}
\hline \multirow{2}{*}{} & \multirow{2}{*}{$\mathbf{q}\left[\mathbf{m}^{\mathbf{3}} / \mathbf{s}\right]$} & \multicolumn{2}{|c|}{$\begin{array}{c}\text { Basic parameters obtained by } \\
\text { hydraulic calculations* }\end{array}$} & \multicolumn{2}{c|}{$\begin{array}{c}\text { Basic parameters obtained } \\
\text { through GIS calculations }\end{array}$} \\
\cline { 3 - 6 } & $\begin{array}{c}\text { Total Flooded } \\
\text { Area }\left[\mathbf{k m}^{2}\right]\end{array}$ & $\begin{array}{c}\text { Total Water } \\
\left.\text { Volume[10 } \mathbf{~ m}^{\mathbf{3}}\right]\end{array}$ & $\begin{array}{c}\text { Total Flooded } \\
\text { Area }\left[\mathbf{K m}^{\mathbf{2}}\right]\end{array}$ & $\begin{array}{c}\text { Total Water } \\
\text { Volume }\left[\mathbf{1 0}^{\mathbf{6}} \mathbf{~ m}^{\mathbf{3}}\right]\end{array}$ \\
\hline 1 & 700.00 & 7,1 & 19.9 & 8,9 & 30,5 \\
\hline 2 & 800.00 & 7,3 & 22.5 & 8,9 & 30,5 \\
\hline 3 & 900.00 & 7,3 & 24.2 & 8,9 & 30,5 \\
\hline 4 & 1000.00 & 7,4 & 26.1 & 8,9 & 30,5 \\
\hline
\end{tabular}

* The hydraulic model was developed by Hydrogeomplekt, LTD within the framework of complex expertise

When comparing the two areas (modelled and calculated by GIS) only within the boundaries of the city of Mizia, the overlap is greater than $90 \%$. Thus, the specified maximum runoff of the high wave corresponds to the depth of flooding HQ 10,000/0.01\%. [2] (Table. 3) 
Table 3. Maximum dimensional water quantities for HMS Skat river at the city of Mizia

\begin{tabular}{|c|l|l|l|r|}
\hline T & $\mathrm{P}$ & $\mathrm{Q}_{\operatorname{maxp}}$ & $\mathrm{Q}-95 \%$ & $\mathrm{Q}+95$ \\
\hline year & $\%$ & $\mathrm{~m}^{3} / \mathrm{s}$ & $\mathrm{m}^{3} / \mathrm{s}$ & $\mathrm{m}^{3} / \mathrm{s}$ \\
\hline 10000 & 0.01 & 933 & 243 & 1625 \\
\hline 2000 & 0.05 & 603 & 202 & 1004 \\
\hline 1000 & 0.1 & 491 & 181 & 801 \\
\hline 200 & 0.5 & 290 & 131 & 449 \\
\hline 100 & 1 & 228 & 111 & 338 \\
\hline 50 & 2 & 170 & 91 & 248 \\
\hline 20 & 5 & 112 & 67 & 157 \\
\hline 10 & 10 & 77 & 50 & 105 \\
\hline 5 & 20 & 49 & 34 & 64 \\
\hline
\end{tabular}

\section{CONCLUSION}

As a result of the applied integrated GIS approach and hydraulic calculations the following conclusions can be drawn

- The flooded area of the town and it's surroundings was reconstructed with a high degree of credibility as regards the flood which manifested on 03.08. - 07.08.2014;

- The volume of the high wave is determined. The instantaneous volume is calculated in the range $26.1-30,5.10^{6} \mathrm{~m}^{3}$. Thus the volume of the high wave formed from 00.00 am on 03.08 .2014 to $12.00 \mathrm{~h}$ on 05.08 .2014 is estimated to be $80.83 .10^{6} \mathrm{~m}^{3}$;

- On the basis of the reconstructed flooded area a 1D hydraulic model is adapted in which the best compliance is sought between the reconstructed and modelled flooded area. Simulations in various water quantities indicate that such compliance is achieved by $\mathrm{Q}=1000 \mathrm{~m}^{3} / \mathrm{s}$. This water quantity corresponds to the water quantity with the probability $\mathrm{P}=0.01 \%$ (recurrence period $10000 \mathrm{y}$.);

- In this way the integrated GIS and hydraulic calculations approaches is determined and the maximum outflow of the high wave $-\mathrm{Q}=1000 \mathrm{~m}^{3} / \mathrm{s}$;

- Depth of flooding in the urbanized part of the town of Mizia is in the range $4-4.7 \mathrm{~m}$, and in the non-urban area part it reaches about $6.0 \mathrm{~m}$.

\section{REFERENCES}

[1] Detailed project "Correction of the river Skat in the area of the city of Mizia"-performed by "Art-Design" LTD. Sofia and handed over to the assignor MRDPW in 2007 year;(In Bulg)

[2] Lisev, N., Analysis of the causes of the flooding of the city. Mizia from August 2014;(In Bulg)

[3] Organizational and technical expertise in pre-litigation no 237/05.08.2014, on the office of Prosecution Oryahovo, 2014.(In Bulg.) 